\title{
LAYANAN DAN INFORMASI AKADEMIK BERBASIS BOT TELEGRAM DI PROGRAM STUDI TEKNIK INFORMATIKA UNIVERSITAS MATARAM
}

\author{
(Information Sharing and Academic Services Based on Telegram BOT in Informatics \\ Engineering Department of Mataram University)
}

\author{
Ariyan Zubaidi", Ramdani \\ Informatics Engineering Department, Mataram University \\ JI. Majapahit 62, Mataram, Lombok NTB, INDONESIA \\ Email : zubaidi13@unram.ac.id, ramdaninformatika@gmail.com
}

\begin{abstract}
Chatbot is considered as one of the hottest technology in recent years. It is used by various sector to serve its customer automatically. It gives benefits to business, primarily in customer care. Chatbot can be divided into 2 (two) types. One operates based on set of rules. It can be used with set of specifics command. The second type uses machine learning and artificial intelligence to provide its services. Chatbot can be utilized as well in education sector. Campus gives services to its students or faculty by providing information and academic services. Commonly, academic information and services has supported by information technology, usually in particular website. However, not all of the services are available and newest information did not always be accessed on time. Hence, this research built a chatbot based on Telegram bot to provide information and academic services in Informatic Engineering Department of Mataram University. Telegram provides API that can be used to develop bot. The bot is built using Python, SQLite and React JS. Prototyping model is used as a development method. The bot prototype is able to broadcast newest information to its register user and provides academic services such as theses and internship services.
\end{abstract}

Keywords: Chatbot, Telegram, Academic Services, Python, Prototyping Model

*Penulis korespondensi

\section{Pendahuluan}

Banyak teknologi yang sedang tren saat ini yang dapat diimplementasikan untuk membantu pekerjaan manusia. Salah satu teknologi yang sedang 'naik daun' adalah chatbot. Menurut Cherryleaf [1], para ahli teknologi menganggap bahwa chatbot merupakan salah satu teknologi yang sangat baik perkembangannya. Hal ini diperlihatkan dengan banyaknya chatbot yang aktif di berbagai platform. Misalnya pada messenger Facebook, per April 2017, terdapat lebih dari 100.000 chatbot yang aktif perbulannya [2]. Chatbot ini disediakan untuk melayani pelanggan untuk kebutuhan bisnis [3]. Selain data tersebut, secara keseluruhan, chatbot telah digunakan di berbagai sektor, mulai dari retail/e-commerce, kesehatan, komunikasi, perbankan, asuransi, dan yang lainnya. Persentasi penggunaan chatbot dapat dilihat pada Gambar 1.

Dari penelitian yang dilakukan oleh Gartner pada [4], terdapat peningkatan yang sangat signifikan dalam penggunaan chatbot dan akan mengalami perkembangan besar pada beberapa tahun mendatang. Ekspektasi yang besar terhadap keuntungan dari penggunaan chatbot akan terus meningkat sejak 2 hingga 5 tahun yang ditunjukkan pada Gambar 2.

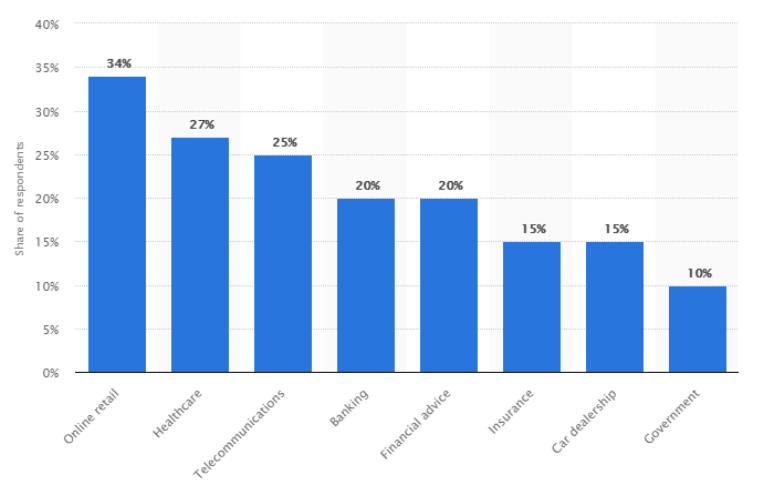

Gambar 1. Komposisi Penggunaan Chatbot di Berbagai Sektor oleh Konsumen di Seluruh Dunia[3].

Pemanfaatan teknologi chatbot selain di berbagai sektor yang telah disebutkan, dapat juga dimanfaatkan di dunia pendidikan. Pada dasarnya, berbagai layanan 
yang disediakan oleh kampus telah didukung oleh penggunaan teknologi informasi. Umumnya, layanan dan informasi disediakan di suatu website yang dapat diakses oleh mahasiswa dan dosen. Namun, tidak semua layanan tercakupi di dalam website dan informasi terbaru seringkali terlewatkan karena civitas akademika tidak setiap hari mengakses website tersebut.

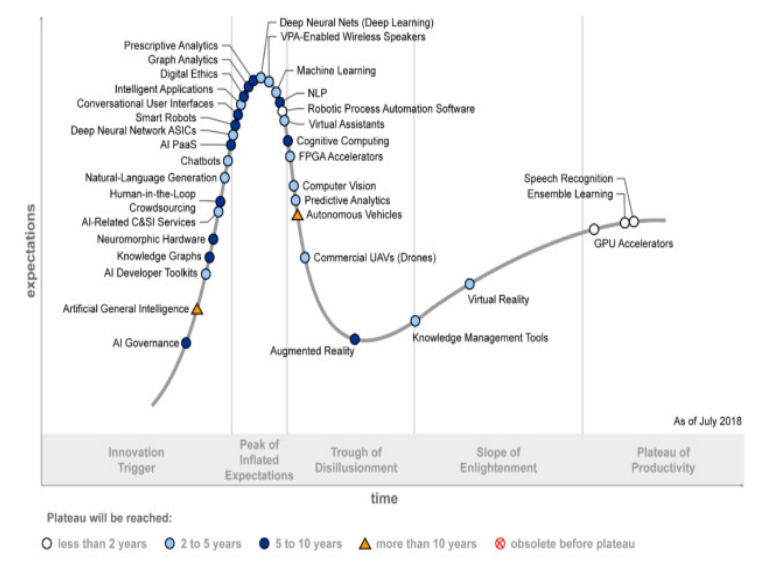

Gambar 2. Siklus Tren Teknologi untuk Kecerdasan Buatan 2018 [4].

Pengembangan chatbot berbasis Telegram ini akan diimplementasikan untuk memberikan informasi dan menyediakan layanan di Program Studi Teknik Informatika (PSTI) Universitas Mataram. Chatbot ini akan membantu staff administrasi dalam melayani mahasiswa yang memerlukan pelayanan akademik sehingga mahasiswa dapat mengakses layanan melalui smartphone yang dimiliki. Mahasiswa dapat mengakses layanan dari mana saja dan hanya perlu ke bagian akademik untuk mengumpulkan atau mengesahkan dokumen yang diperlukan.

\section{TINJAUAN PUStaka}

Beberapa penelitian terkait telah dilakukan, diantaranya oleh Setiaji [5] yang mengembangkan bot Telegram untuk mendukung sharing informasi di Kampus. Dalam pengembangannya menggunakan webhooks dengan kelebihan zero latency dan dapat menangani multiple request secara bersamaan di dalam komunikasi melalui bot Telegram. Pada penelitian lainnya yang dilakukan oleh [6], dilakukan otomatisasi layanan kampus berupa pencarian informasi mengenai kampus, jadwal, hingga pengisian formulir yang dibutuhkan melalui bot Telegram. Aplikasi telegram dipilih karena bersifat gratis, cepat dan dapat berjalan pada berbagai platform.
Pada penelitian yang dilakukan oleh [7], telah diidentifikasi bahwa terdapat ketertarikan yang besar terhadap penggunaan chatbot untuk mengotomatisasi layanan. Hal ini didukung dengan perkembangan layanan messenger yang terus berkembang ditambah lagi kemajuan di bidang kecerdasan buatan yang membawa kepada penggabungan layanan chatbot dan implementasi teknik kecerdasan buatan. Hal ini pun sudah diimplementasikan pada [8] yang membuat bot Telegram yang mampu mengklasifikasikan jenis daun berdasarkan gambar daun yang diunggah ke bot Telegram. Aplikasi yang dinamakan Botanicum dapat mengidentifikasi 20 jenis spesies daun yang hidup di Rusia. Akurasi klasifikasi yang didapatkan mencapai 97.8\%. Pemilihan messenger Telegram didasarkan pada kemudahan yang disediakan oleh Telegram bagi developer untuk membuat bot dengan fungsionalitas yang beragam.

Pada penelitian lainnya, Nufusula [9] mengembangkan chatbot Telegram untuk melayani pengisian pulsa secara otomatis. Pengguna dapat mengisi pulsa dari berbagai operator dengan hanya memasukkan perintah-perintah yang sudah disediakan. Metode yang digunakan pada penelitian ini adalah menggunakan metode Long Polling.

Dari penelitian-penelitian yang sudah dijelaskan di atas, bahwa penggunaan Telegram sebagai media untuk mengembangkan bot dengan berbagai fungsi sangat mungkin dilakukan karena telah disediakan BOT API (Application Programming Interface) yang dapat digunakan untuk pengembangan berbagai bot dengan fungsi yang berbeda-beda. Selain itu kemudahan dalam implementasi dan dapat berjalan pada berbagai macam platform juga menjadi pertimbangan pemilihan Telegram.

\subsection{Dasar Teori}

\subsubsection{Chatbot}

Chatbot adalah sebuah layanan dimana orang akan berinteraksi dengannya melalui antarmuka chat. Chatbot akan merespon dalam gaya yang konversasional, dan dapat melakukan suatu tindakan dari konversasi tersebut. Chatbot biasanya berjalan pada aplikasi messenger populer, seperti Facebook Messenger, Twitter, WhatsApp, dan Telegram. Terdapat 2 (dua) tipe chatbot [1]:

a. Chatbot yang beroperasi berdasarkan sekumpulan aturan. Hanya dapat merespon berdasarkan command yang spesifik. Jika seseorang menggunakan selain command atau 
kata yang sudah ditentukan, maka chatbot tidak akan mengerti maksud orang tersebut.

b. Chatbot yang menggunakan machine-learning (ML) dan artificial intelligence (Al) untuk menyediakan respon terbaik. Biasa dinamakan dengan Al-powered chatbot.

\subsubsection{Telegram}

Telegram adalah layanan IM populer yang berbasis open-source platform. Menawarkan layanan yang gratis tanpa pembayaran apapun, selain itu menawarkan lingkungan yang bebas dari iklan dengan antarmuka yang cepat dan bersih. Telegram dibuat pada tahun 2013 oleh teknokrat asal Rusia Pavel Duvrov. Keberadaan Telegram mendapat tantangan serius dari kompetitornya seperti Whatsapp dan Viber. Popularitas Telegram meningkat karena menjadi aplikasi yang paling banyak diunduh di Google Playstore [10].

Penggunaan Telegram sangat mudah. Pengguna cukup melakukan registrasi dengan menggunakan nomor handphone untuk menggunakannya. Terdapat banyak kesamaan dengan antara Telegram dan Whatsapp dalam hal ID pengguna dan kontak. Nomor handphone digunakan sebagai identifikasi utama pengguna. Telegram memiliki kelebihan, diantaranya sticker shop yang dapat digunakan pada waktu chatting disamping penggunaan teks. Telegram dapat digunakan untuk berbagi dokumen dalam berbagai jenis tanpa batasan ukuran. Telegram adalah aplikasi yang multi-platform, dapat berjalan di Android, iOS, Windows Phone, Mac dan Windows [10].

\subsubsection{Web service}

Web services adalah suatu sistem perangkat lunak yang dikembangkan untuk mendukung komunikasi antara 2 (dua) host mesin pada suatu jaringan. Komunikasi dapat dilakukan melalui HTTP (Hyper Text Transfer Protocol) menggunakan teknologi seperti XML (Extensive Markup Languange), SOAP (Simple Object Acces Protocol), WSDL (Web service Description Language), dan UDDI (The Universal Description, Discovery and Integration). Konsep arsitektur yang mendasari teknologi Web service adalah Service Oriented Architecure (SOA), SOA mendefinisikan 3 peran berbeda yang menunjukkan peran dari masingmasing komponen dalam sistem, yaitu [11]:

a. Service provider, yaitu suatu entitas yang menyediakan web service yang menjalankan sekumpulan tugas tertentu. b. Service requestor, yaitu suatu entitas yang meminta suatu fungsionalitas tertentu dari web service.

c. Service registry, yaitu entitas yang menyimpan berbagai service yang disediakan oleh Service Provider.

\subsubsection{Python}

Python merupakan bahasa pemrograman umum yang mencampurkan paradigma pemrograman prosedural, fungsional, dan object-oriented [12]. Python banyak digunakan karena memberikan berbagai kelebihan bagi penggunanya, seperti meningkatkan produktivitas, kualitas perangkat lunak, portabelitas program, mendukung banyak library, dan memudahkan integrasi komponen [12].

Bahasa Python banyak digunakan untuk menghasilkan berbagai produk oleh perusahaanperusahaan besar, seperti [12]:

a. Google, menggunakan bahasa Python secara luas di mesin pencariannya.

b. Youtube, menyediakan layanan video-sharing dikembangkan menggunakan Python.

c. Dropbox, mengembangkan software client dan server sebagian besar menggunakan Python.

d. Maya, program yang digunakan untuk pemodelan animasi dan 3-dimensi, menyediakan API Python.

\section{Metode Penelitian}

\subsection{Metode Pengembangan Sistem}

Metode pengembangan sistem pada penelitian ini menggunakan model prototyping. Pada model ini, tahapannya terdiri pengumpulan kebutuhan, proses desain yang cepat, membangun prototipe, evaluasi dan perbaikan [13]. Siklus model pengembangan ini dapat dilihat pada Gambar 3.

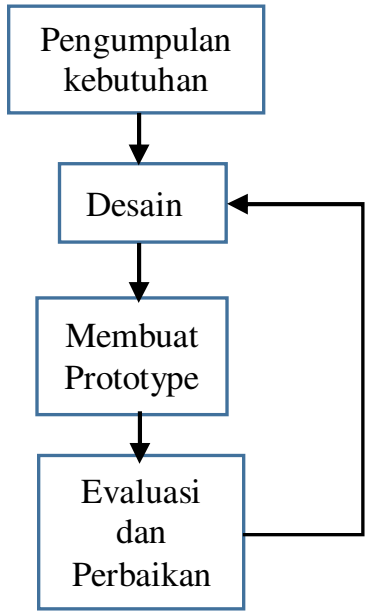

Gambar 3. Model Pengembangan Prototyping. 
Pengumpulan kebutuhan dilakukan dengan melibatkan bagian akademik sebagai penyedia layanan di PSTI. Pada tahap ini diidentifikasi apa saja layanan yang perlu disediakan di chatbot yang akan dikembangkan. Setelah mengetahui kebutuhan, langkah berikutnya adalah mendesain sistem yang akan dikembangkan. Pada penelitian ini, menggunakan diagram use case, untuk menggambarkan fungsi-fungsi apa saja yang ada di chatbot dan pengguna yang terlibat. Untuk memberikan gambaran teknologi yang terlibat, didesain juga arsitektur chatbot.

Langkah berikutnya adalah membuat prototype dari chatbot yang sudah didesain sebelumnya. Pengembangan chatbot ini menggunakan tools sebagai berikut :

b. React JS digunakan untuk membuat website yang digunakan oleh admin untuk mengirim informasi ke pengguna.

c. SQL Lite digunakan untuk membuat database yang menyimpan data pengguna yang terdaftar pada server.

Setelah prototype chatbot dibangun, maka dilakukan evaluasi dan perbaikan dengan melibatkan bagian akademik untuk melihat apakah prototype yang dibangun sudah sesuai dengan kebutuhan di bagian akademik PSTI. Proses ini akan terus berulang sampai pada titik bahwa prototype sudah memenuhi semua kebutuhan yang diperlukan.

\subsection{Kebutuhan Sistem}

Dari proses pengumpulan kebutuhan yang dilakukan, maka didapatkan kebutuhan-kebutuhan yang menjadi prioritas untuk dimasukkan ke dalam sistem yang dikembangkan. Kebutuhan-kebutuhan yang diperlukan saat ini adalah :

a. Penyebaran informasi terbaru di PSTI yang dapat diterima dengan cepat oleh dosen dan mahasiswa.

b. Staf akademik dapat mengurangi hal-hal yang bersifat repetitif seperti menjawab pertanyaan mahasiswa mengenai suatu layanan. Misalnya, mahasiswa ingin mendaftar PKL atau TA, maka biasanya mahasiswa akan menanyakan langkahlangkah yang dilakukan ke staf akademik.
Bagaimana hal ini dapat dikurangi dengan adanya panduan bagi mahasiswa,

c. Mahasiswa memiliki panduan penulisan TA atau PKL yang mudah diakses .

Kebutuhan fungsional dari sistem yang didapatkan dari analisis kebutuhan yang ada di PSTI adalah :

a. Admin dapat memasukkan informasi terbaru di PSTI melalui laman web khusus. Informasi ini akan masuk ke chatbot pengguna yang terdaftar di akun bot Telegram.

b. Pengguna dalam hal ini mahasiswa, dapat mengakses layanan-layanan, yaitu :

1. Layanan Tugas Akhir, mencakup Tugas Akhir 1 dan Tugas Akhir 2.

2. Layanan Praktek Kerja Lapangan.

3. Tata tulis Praktek Kerja Lapangan dan Tugas Akhir.

\subsection{Perancangan Sistem}

\subsubsection{Usecase Diagram}

Terdapat dua aktor dalam chatbot ini yaitu User dan Admin. Admin dapat melakukan Broadcast Message atau mengirim informasi terbaru ke pengguna bot yang sudah terdaftar. User terdiri dari Mahasiswa dan Dosen. User dapat mengakses beberapa fitur seperti melihat beberapa informasi yang disediakan antara lain Informasi Praktek Kerja Lapangan, Tugas Akhir, Aturan Penulisan Laporan dan menerima notifikasi berupa informasi terbaru yang di-broadcast oleh Admin. Use case dari chatbot yang dikembangkan dapat dilihat pada Gambar 4.

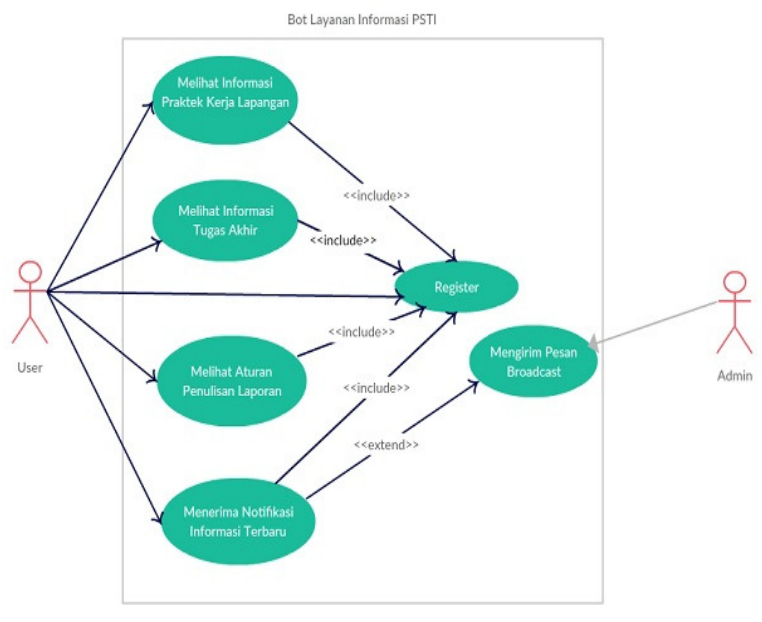

Gambar 4. Use case Bot Layanan PSTI 


\subsubsection{Arsitektur Chatbot}

Terdapat beberapa teknologi seperti Telegram yang merupakan aplikasi dimana Bot berjalan yang dapat dilihat dan diakses oleh User, Python (Python Telegram Bot) dan SQLite untuk pengaturan respon dari request yang dilakukan oleh User melalui Bot Telegram, serta website yang dibangun dengan ReactJs yang hanya dapat diakses oleh Admin untuk melakukan pengiriman pesan ke User melalui API yang disediakan oleh Telegram. Arsitektur chatbot dapat dilihat pada Gambar 5.

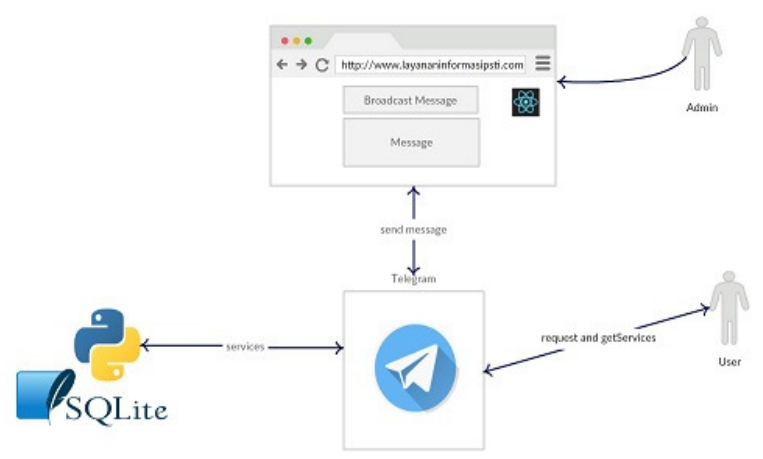

Gambar 5. Arsitektur Chatbot.

\subsubsection{Rancangan Database}

Untuk menyimpan pengguna yang sudah terdaftar pada chatbot, maka dibuat satu tabel pengguna. Detail tabel pengguna dapat dilihat pada tabel I.

tabel I. Detall Tabel Pengguna

\begin{tabular}{|c|c|}
\hline Field & Type Data \\
\hline$\underline{\text { id }}$ & integer \\
\hline Firstname & Text \\
\hline Nama & Text \\
\hline Email & Text \\
\hline Status & Text \\
\hline
\end{tabular}

\section{HASIL dAN PEMBahasan}

\subsection{Implementasi}

Pembuatan bot Telegram memerlukan proses registrasi bot yang dilakukan melalui aplikasi Telegram dengan mengakses akun BotFather. Rangkaian API key akan diberikan sebagai penanda untuk setiap request ke server Telegram.

Pengguna yang mengakses bot Layanan PSTI akan dicek terlebih dahulu apakah sudah terdaftar atau tidak, jika belum terdaftar maka akan diarahkan untuk mendaftar, jika sudah terdaftar maka dapat mengakses layanan yang tersedia. Layanan-layanan yang disediakan beserta keterangan lainnya seperti command yang digunakan, sifat pesan apakah multi pesan yaitu layanan yang memerlukan pesan lanjutan atau satu pesan yaitu layanan yang hanya memerlukan satu pesan saja. Output yang dihasilkan setiap layanan dapat berbentuk respon teks atau respon berupa dokumen. Layanan secara lengkap dapat dilihat di tabel 2.

TABEL 2. LAYANAN-LAYANAN PADA Bot PSTI

\begin{tabular}{|c|c|c|c|}
\hline Service & Command & $\begin{array}{c}\text { Sifat } \\
\text { Pesan }\end{array}$ & Output \\
\hline Registrasi & /daftar & $\begin{array}{c}\text { Multi } \\
\text { message }\end{array}$ & Text \\
\hline Layanan TA & /layananta & $\begin{array}{c}\text { Multi } \\
\text { message }\end{array}$ & $\begin{array}{c}\text { Text / } \\
\text { dokumen }\end{array}$ \\
\hline Layanan PKL & /layananpkl & $\begin{array}{c}\text { Multi } \\
\text { message }\end{array}$ & $\begin{array}{c}\text { Text / } \\
\text { dokumen }\end{array}$ \\
\hline Tata tulis & /tatatulis & $\begin{array}{c}\text { Multi } \\
\text { message }\end{array}$ & $\begin{array}{c}\text { Text / } \\
\text { dokumen. }\end{array}$ \\
\hline
\end{tabular}

\subsubsection{Registrasi}

Ketika user pertama kali join ke bot Telegram maka user akan diarahkan untuk melakukan registrasi terlebih dahulu untuk dapat mengakses layanan yang disediakan. User akan diminta untuk mengisi beberapa data berupa Nama, NIM or NIP, serta Email. Ketika data sudah dilengkapi maka user dapat men-submit dengan memilih "Done" atau jika user ingin meperbarui data atau update data maka user dapat memilih data yang ingin di-update dan pilih "Done". User akan dapat dikategorikan sebagai Mahasiswa atau Dosen dari data yang dimasukkan ke NIM or NIP, yang nantinya akan dibandingkan pada data user yang disediakan di database. Tampilan chatbot untuk proses registrasi dapat dilihat pada Gambar 6.

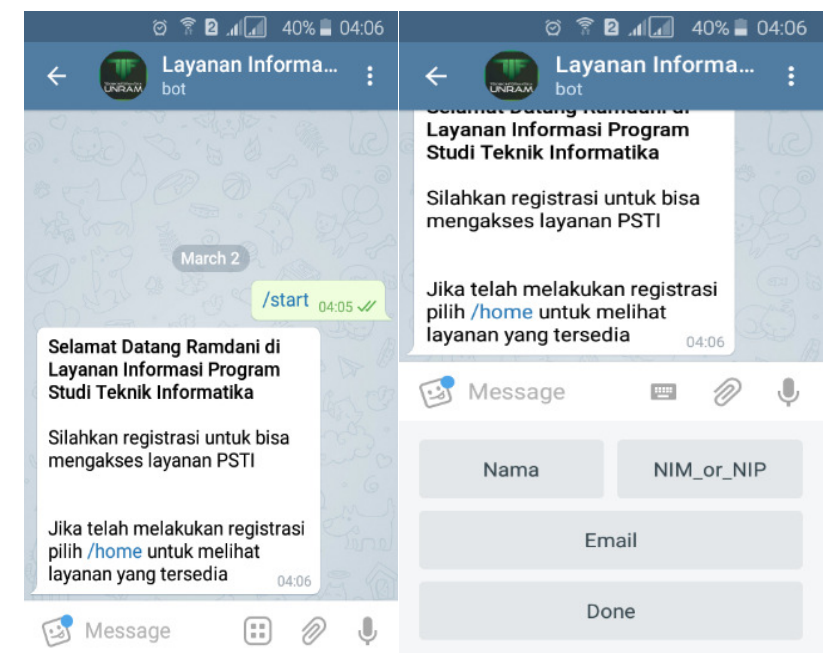

Gambar 6. Tampilan chatbot untuk proses registrasi 


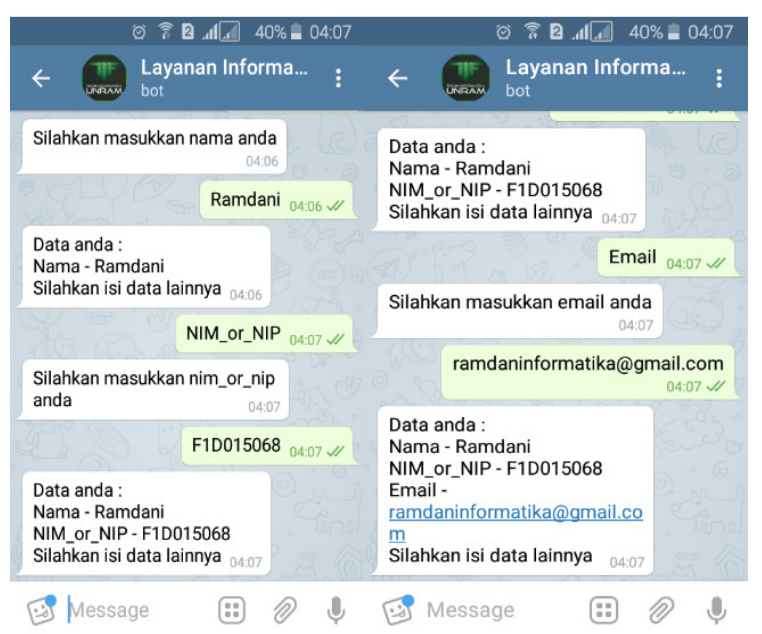

Gambar 7. Proses Registrasi

\subsubsection{Akses Layanan PKL}

Informasi Praktek Kerja Lapangan memberikan tiga layanan antara lain Informasi berupa Pendaftaran, Seminar dan Pembukuan Praktek Kerja Lapangan. Proses pengaksesan layanan PKL dapat dilihat pada Gambar 8.

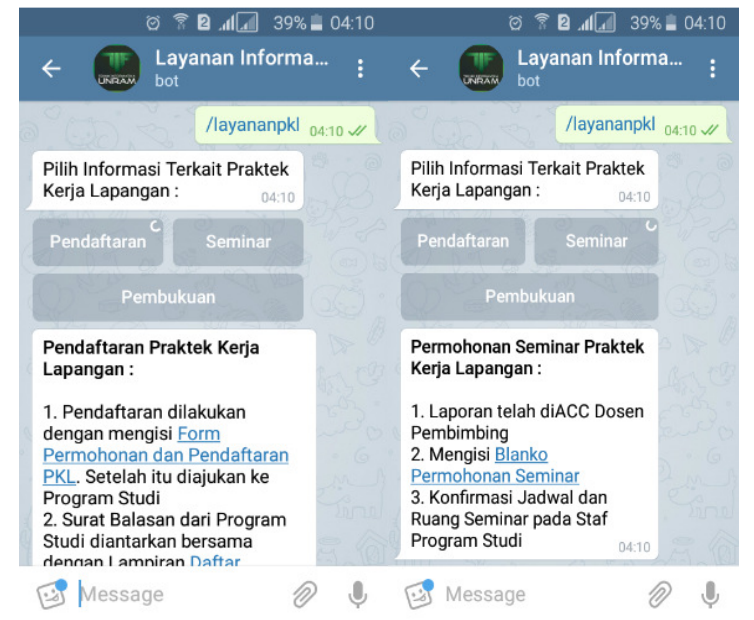

Gambar 8. Akses Layanan PKL

\subsubsection{Akses Layanan TA}

Informasi Tugas Akhir memberikan dua layanan antara lain Informasi Tugas Akhir 1 dan Tugas Akhir 2 yang masing-masing juga terdapat tiga informasi berupa Pendaftaran, Seminar dan Pembukuan. Proses pengaksesan layanan TA dapat dilihat pada Gambar 9.

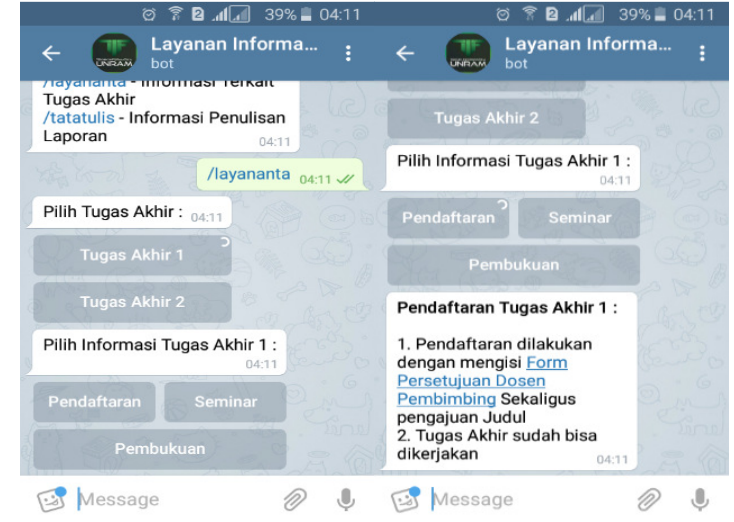

Gambar 9. Akses Layanan TA.

\subsubsection{Akses Layanan Tata Tulis}

Informasi Penulisan Laporan memberikan dua layanan yaitu Informasi berupa Penulisan Laporan Praktek Kerja Lapangan dan Penulisan Laporan Tugas Akhir. Proses pengaksesan layanan tata tulis dapat dilihat pada Gambar 10.

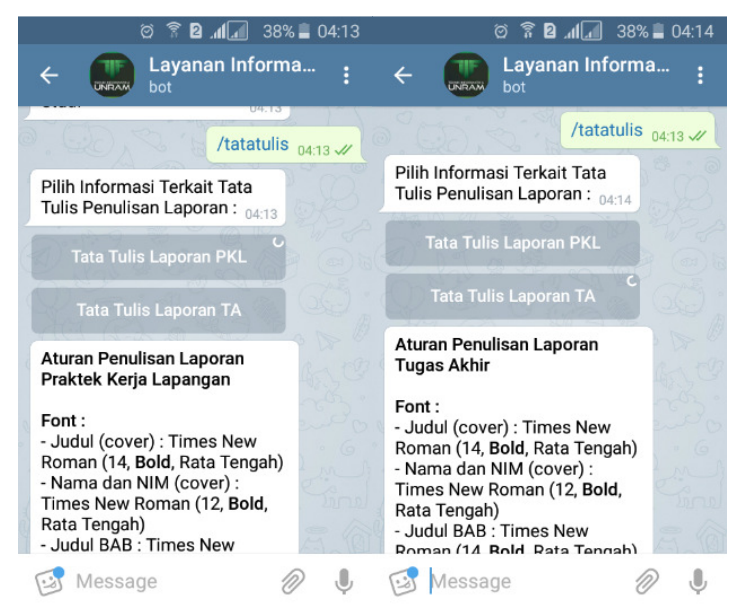

Gambar 10. Akses Layanan Tata Tulis

\subsubsection{Memasukkan Informasi (Broadcast Message)}

Broadcast Message merupakan fitur berbasis web dapat diakses oleh Admin untuk memberikan pesan ke User Mahasiswa atau Dosen atau semuanya. Proses penginputan informasi melalui web admin dapat dilihat pada Gambar 11. Pesan/informasi yang dimasukkan akan diterima oleh pengguna yang ditunjukkan pada Gambar 12. 


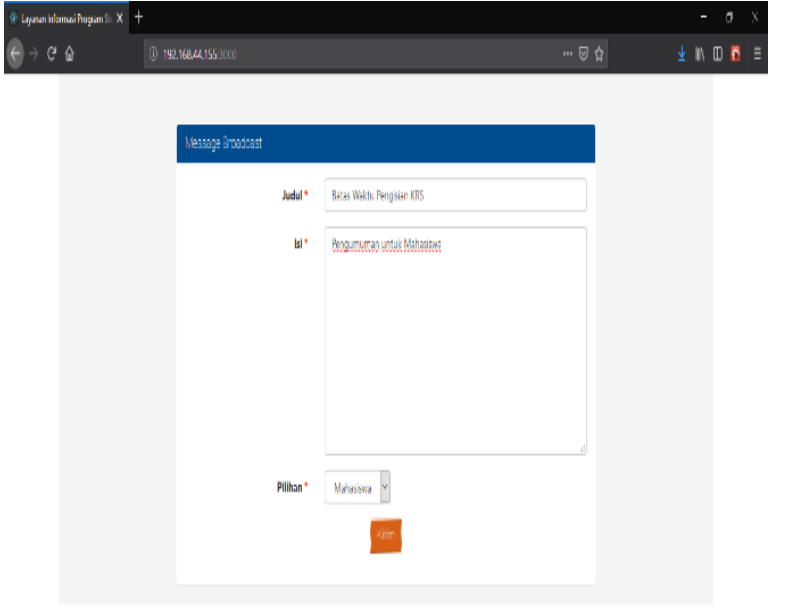

Gambar 11. Memasukkan Informasi Melalui Laman Web Admin.

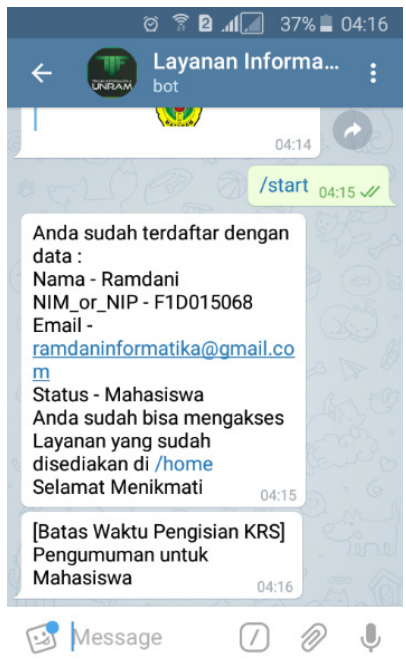

Gambar 12. Penerimaan Pesan oleh Pengguna (Mahasiswa)

\subsection{Pengujian}

Pengujian chatbot dilakukan dengan metode blackbox. Setiap fungsi diuji dengan menjalankan command yang disediakan untuk masing-masing layanan. Dari pengujian yang dilakukan, setiap layanan dapat diakses menggunakan command yang disediakan. Rangkuman hasil pengujian dapat dilihat pada tabel 3.

TABEL 2. LAYANAN-LAYANAN YANG TERSEDIA

\begin{tabular}{|l|l|c|c|}
\hline Layanan & Command & $\begin{array}{c}\text { Jumlah } \\
\text { Pengujian }\end{array}$ & Keberhasilan \\
\hline Registrasi & /daftar & 5 & $100 \%$ \\
\hline $\begin{array}{l}\text { Layanan } \\
\text { TA }\end{array}$ & /layananta & 5 & $100 \%$ \\
\hline
\end{tabular}

\begin{tabular}{|l|l|c|c|}
\hline Layanan & Command & $\begin{array}{c}\text { Jumlah } \\
\text { Pengujian }\end{array}$ & Keberhasilan \\
\hline $\begin{array}{l}\text { Layanan } \\
\text { PKL }\end{array}$ & $\begin{array}{l}\text { /layananp } \\
\mathrm{kl}\end{array}$ & 5 & $100 \%$ \\
\hline Tata tulis & /tatatulis & 5 & $100 \%$ \\
\hline
\end{tabular}

\section{KeSIMPULAN DAN SARAN}

\subsection{Kesimpulan}

Chatbot berbasis Telegram telah dibangun dengan menyediakan berbagai layanan seperti penyediaan informasi, layanan tugas akhir, layanan praktek kerja lapangan dan tata tulis. Dari hasil pengujian yang telah dilakukan, command untuk masing-masing layanan dapat dieksekusi dengan baik dan memberikan respon sesuai yang diinginkan.

\subsection{Saran}

Beberapa saran dari penelitian ini adalah :

a. Layanan-layanan lainnya dapat ditambahkan untuk melengkapi layanan yang sudah ada di bot Telegram PSTI.

b. Pada penelitian ini, chatbot yang dikembangkan adalah tipe chatbot yang berjalan dengan menerima sekumpulan command. Untuk pengembangan berikutnya, perlu dicoba chatbot yang menggunakan machine learning dan artificial intelligence.

\section{DAFTAR PUSTAKA}

[1] E. P. Cherryleaf, "A Primer Artificial Intelligence and Chatbots in Technical Communication," liblog, p. 2, 2017.

[2] F. Daniel, M. Matera, V. Zaccaria, and A. Dell'Orto, "Toward Truly Personal Chatbots On: On the Development of Custom Conversational Assistants Florian," Proc. 1st Int. Work. Softw. Eng. Cogn. Serv. - SE4COG '18, pp. 31-36, 2018.

[3] Brain, "Chatbot Report 2018: Global Trends and Analysis," 2018. [Online]. Available: https://chatbotsmagazine.com/chatbot-report2018-global-trends-and-analysis-4d8bbe4d924b. [Accessed: 03-Feb-2018].

[4] S. Sicular and K. Brant, "Hype Cycle for Artificial Intelligence, 2018," no. July, p. Gartner, Inc., 2018.

[5] H. Setiaji and I. V Paputungan, "Design of Telegram Bots for Campus Information Sharing Design of Telegram Bots for Campus Information Sharing," 2018.

[6] G. Sastrawangsa, "Pemanfaatan Telegram Bot Untuk Automatisasi Layanan Dan Informasi Mahasiswa Dalam Konsep Smart Campus," Konf. Nas. Sist. 
Inform., pp. 772-776, 2017.

[7] Accenture, "Chatbots In Customer Service," 2016.

[8] D. Korotaeva, M. Khlopotov, A. Makarenko, E. Chikshova, and N. Startseva, "Botanicum: a Telegram Bot for Tree Classification," in Proceeding of The 22nd Conference Of Fruct Association, 2018.

[9] R. Nufusula and A. Susanto, "Rancang Bangun Chat Bot Pada Server Pulsa Mengunakan Telegram Bot API," J. Inf. Syst., vol. 3, no. 1, pp. 80-88, 2018.

[10] T. Sutikno, L. Handayani, D. Stiawan, M. A. Riyadi, I. Much, and I. Subroto, "Whatsapp , Viber and Telegram: which is the Best for Instant
Messaging ?," Int. J. Electr. Comput. Eng., vol. 6, no. 3, pp. 909-914, 2016.

[11] W3C, "Web Service Architecture," W3C Working Group Note, 2004. [Online]. Available: https://www.w3.org/TR/ws-arch/. [Accessed: 14Feb-2019].

[12] M. Lutz, Learning Python, 5th Edition. O’Reilly, 2013.

[13] P. M. Ogedebe and B. P. Jacob, "Software Prototyping: A Strategy to Use When User Lacks Data Processing Experience," ARPN J. Syst. Softw., vol. 2, no. 6, pp. 219-224, 2012. 